\title{
Tolerability and Efficacy of a Medical Device Repairing Emollient Cream in Children and Adults with Mild to Moderate Atopic Dermatitis
}

\author{
Andreas Pinter · Marie-Dominique Thouvenin · Adeline Bacquey • \\ Ana Beatris Rossi · Thérèse Nocera
}

Received: February 22, 2019 / Published online: April 9, 2019

(C) The Author(s) 2019

\begin{abstract}
Introduction: Regular emollient application is recommended for managing atopic dermatitis (AD). Although many emollients are available, only AD-tested medical device repairing emollient creams (MDRECs) can be recommended for treating and preventing $\mathrm{AD}$ skin lesions. Here, we evaluated the tolerability and benefit of a new MDREC in an open-label study in infants, young children, and adults with mild to moderate AD.

Methods: Subjects (or their parents or guardians) were instructed to apply the MDREC to $\mathrm{AD}$ lesions or areas of dry skin twice daily for 3 weeks. Investigators assessed tolerability and
\end{abstract}

Enhanced Digital Features To view enhanced digital features for this article go to https://doi.org/10.6084/ m9.figshare.7934222.

\section{A. Pinter}

Department of Dermatology, Venereology and Allergology, Clinical Research Division, University Clinic Frankfurt am Main, Frankfurt am Main, Germany

M.-D. Thouvenin · A. Bacquey · A. B. Rossi ·

T. Nocera $(\bowtie)$

Clinical Skin Research and Development Center,

Hôtel Dieu, Pierre Fabre Dermo-Cosmétique,

Toulouse, France

e-mail: therese.nocera@pierre-fabre.com

A. B. Rossi

Dermatology Department, Larrey University

Hospital, Toulouse, France
AD severity at days 1,8 , and 22 . Subjects assessed AD severity weekly, recorded any adverse events, and reported their satisfaction with the MDREC at day 22.

Results: Sixty-one subjects (19 infants, 22 children, and 20 adults) were included and 59 completed the study. At inclusion, $49 \%$ of the infants and young children and $15 \%$ of the adults were experiencing flares of AD. At day 22, the local tolerability of the MDREC was judged by the investigators as excellent in all the children and in 18 of the 20 adult subjects (90\%). All adverse events were mild and transient. Investigator- and subject-assessed AD severity progressively decreased at each assessment for each age subgroup.

Conclusion: This study shows that the MDREC was well tolerated when applied to AD skin lesions in infants, young children, and adults and suggests this product can be used daily to control the signs and symptoms of AD.

Funding: Laboratoires Dermatologiques Ducray, Pierre Fabre Dermo-Cosmétique.

Keywords: Atopic dermatitis; Emollient; Eczema; Skin cream; Tolerability

\section{INTRODUCTION}

Atopic dermatitis (AD) is a common chronic or recurrent inflammatory skin disorder that starts in early childhood and often precedes the 
development of other allergic disorders later in life $[1,2]$. AD affects $15-20 \%$ of children and $1-3 \%$ of adults worldwide, and its incidence has increased in industrialized countries over the past few decades $[1,3]$. The disease is a significant burden on health-care resources and can limit school or work performance, disturb sleep because of itchiness, and lead to social anxiety and depression [4].

Treatment for $\mathrm{AD}$ focuses on repairing or protecting the skin barrier and reducing inflammation and itching. Topical corticosteroids are recommended for treating acute moderate to severe flares, but daily application of an emollient is recommended for preventing and managing $\mathrm{AD}$ lesions $[2,5,6]$. Emollients reduce skin dehydration and permeability to irritants, which protects and resolves skin lesions and helps decrease cutaneous reactivity [5, 7-9]. However, many individuals with AD choose not to use emollients as recommended because of the multiple applications required each day and because some emollients have a greasy texture or disagreeable odor [1, 10]. Although many emollients are available, most are cosmetic products designed to improve the appearance of healthy skin and should not be applied to AD skin lesions [5]. By contrast, medical device repairing emollient creams (MDRECs) are suitable for treating and preventing $A D$. MDRECs for $A D$ should be tested in children because they have AD more frequently, are at increased risk of adverse events (AEs) from topical corticosteroids [11], and have thinner skin than adults [12].

In this study, we examined the tolerability and benefit of a new MDREC in infants, young children, and adults with mild to moderate AD. The MDREC tested is considered a class II medical device [13] and is designed to protect and repair irritated skin, either alone or combined with topical corticosteroids, for individuals at least 3 months of age. The product is formulated free of potential irritant factors and contains natural polysaccharides that form a protective, hydrating invisible film when applied to skin.

\section{METHODS}

\section{Study Design}

This was an open-label, multicenter study in children and adults with mild to moderate AD. The study was performed at six centers in Germany between December 2014 and August 2015. The primary objective was to assess the local tolerability of an MDREC (Dexyane $\mathrm{MeD}^{\circledR}$, Ducray Laboratories, Pierre Fabre Dermo-Cosmétique, Boulogne, France). Secondary objectives included assessments of the local tolerability of the MDREC $30 \mathrm{~min}$ after the first application and 1 week after twice-daily application; its efficacy in improving $\mathrm{AD}$; and the subject (or parent or guardian) overall satisfaction with the MDREC. The study protocol was approved by the Ethics Committee of the Medical University Department of University Clinic Frankfurt am Main, Germany, performed in accordance with the Declaration of Helsinki and national regulations, and was in compliance with Good Clinical Practice (EN ISO 14155:2011). All participating adult subjects, or the participating subject's parents or guardians, provided their written informed consent.

\section{Subjects}

Subjects included in this study had to be 3-23 months (infant group), 2-6 years (young children group), or 18-65 years (adult group) of age; have skin phototype I, II, III, or IV according to the Fitzpatrick classification; have $\mathrm{AD}$ with a scoring atopic dermatitis (SCORAD) index of at least 15 and at most 30 [14], a SCORAD xerosis score of at least 2 (moderate) [14], and an Investigator's Global Assessment (IGA) severity score of 2 or 3 (mild or moderate; scale described below); and have AD lesions or areas of dry skin that covered at most $30 \%$ of the body surface area. The investigator diagnosed $\mathrm{AD}$ based on morphology, distribution of subject skin lesions, historical features, and associated clinical signs, in accordance with established guidelines [15].

Subjects were excluded if they had severe oozing or crusts characteristic of severe AD; any condition other than $\mathrm{AD}$ that could interfere 
with the outcome of the study (e.g., acute bacterial or viral skin infection); ongoing allergen reintroduction; or history of hypersensitivity or intolerance to any component of the test product. Subjects could not be taking phototherapy within 4 weeks before or during the study; topical immunomodulators, topical nonsteroidal anti-inflammatory drugs, topical corticosteroids, topical antihistamines, topical antibiotics, or topical antiseptics applied to the test areas within 5 days before or during the study; skincare products (including moisturizers) applied on the body or face within $4 \mathrm{~h}$ before inclusion (except on the diaper area for infants and children). Subjects and mothers of breastfed child subjects could not be taking systemic non-biological immunosuppressives within 4 weeks before or during the study; systemic biological immunosuppressives within 12 weeks before or during the study; systemic corticosteroids or systemic antihistamines within 2 weeks before or during the study; or antibiotics within 1 week before or during the study. Women were excluded if pregnant, breastfeeding, or of childbearing potential and not using an effective method of contraception for at least 2 months before the study.

\section{Materials}

The MDREC (Dexyane MeD) contained white beeswax, glycyrrhetinic $(\beta)$ acid, hydroxydecenoic acid, cetyl alcohol, glyceryl stearate SG, glyceryl stearate/PEG-100 stearate, Shea butter, capric caprylic triglyceride $30 / 70$, polysorbate 60 , sclerotium gum, polyacrylate-13, glycerin, propylene glycol, 1,3-butanediol, disodium ethylenediaminetetraacetic acid, citric acid monohydrate, guanidine carbonate, capryl glycol, and water.

\section{Study Conduct}

The MDREC was first topically applied to the subject's AD lesions or areas of dry skin by the investigator during the inclusion visit (day 1). Subjects were then instructed to apply the MDREC at home on the same test areas twice daily (morning and evening) every day for
3 weeks, even if clinical signs or symptoms of $\mathrm{AD}$ disappeared. If new lesions appeared during the study, subjects were allowed to apply the MDREC but had to inform the investigator at the next visit and could not treat more than $30 \%$ of the body surface area. The MDREC could not be applied to the diaper area. Subjects were withdrawn from the study if their lesions worsened to an extent that treatment was required. Subjects were given study diaries to keep a daily record of MDREC application and to report changes in application frequency, AEs, disease intensity, how lesions responded, and whether they were taking other treatments. Compliance with the regimen was assessed by calculating the ratio of actual number of applications (as reported in the diary) to the theoretical number of twice daily applications considering how many days each patient participated in the study.

\section{Tolerability and Safety Assessments}

The primary outcome measure was the local tolerability of the MDREC on AD lesions between 1 week (day $8 \pm 2$ ) and the end of the study (day $22 \pm 2$ ) as measured by the investigators. Local tolerability was measured on a 5 -point scale, where 1 = excellent (no functional or physical sign from examination), 2 = very good (transitory functional signs and no physical signs from examination), $3=$ good (transitory or persistent functional signs with transitory physical signs), $4=$ moderate (persisting functional or physical signs that necessitate modified MDREC administration), and $5=$ bad (functional or physical signs that necessitate discontinuation). Investigators also assessed the local tolerability $30 \mathrm{~min}$ after the first application on day 1 and after 1 week (day $8 \pm 2$ ) using the same 5-point scale. AEs were recorded by the investigator at each visit using the subject study diaries or following clinical evaluation.

\section{Efficacy Assessments}

Investigators assessed treatment efficacy at day 1,8 , and 22 using the SCORAD index as previously described [14], and an IGA score on a 
6-point scale, where $0=$ clear (no inflammatory signs of $\mathrm{AD}$ ), 1 = almost clear (just perceptible erythema and just perceptible papulation/infiltration), $2=$ mild disease (mild erythema and mild papulation/infiltration), $3=$ moderate disease (moderate erythema and moderate papulation/infiltration), $4=$ severe disease (severe erythema and severe papulation/infiltration), and $5=$ very severe disease (severe erythema and severe papulation/infiltration with oozing/crusting). In adults, investigators also measured transepidermal water loss [TEWL; using the Aquaflux system (Biox Systems, London, UK)] and skin hydration [using the Corneometer ${ }^{\circledR}$ CM 825 system (Courage + Khazaka Electronic GmbH, Cologne, Germany)] of one selected target lesion. Subjects or the subject's parents or guardians assessed treatment efficacy using the patient-oriented SCORAD (POSCORAD) as previously described [16] at days 1 , 8, 15, and 22; and a 5-point patient global assessment (PGA) scale in which AD intensity on days 8,15 , and 22 was compared with baseline $(0=$ worse, $1=$ no change, $2=$ slight improvement, 3 = marked improvement, $4=$ total resolution). Subjects or the subject's parents or guardians also completed a questionnaire at the end of the study in which they rated whether they liked or disliked the product, and assigned a global mark on a scale from 0 (disliked a lot) to 10 (liked a lot). The questionnaire also asked subjects to give their opinion of the MDREC's cosmetic characteristics and acceptability.

\section{Study Size Estimation}

Because this was an open-label tolerability study, no formal sample size calculation was performed. However, statisticians estimated that a sample size of 60 subjects (20 subjects aged 3-23 months, 20 subjects aged 2-6 years, and 20 subjects aged $18-65$ years) was required to fairly assess tolerability related to the MDREC.

\section{Statistical Analysis}

Analyses were performed for all subjects receiving at least one application of the MDREC. Differences in efficacy compared with baseline were determined by Wilcoxon signed-rank test or Student $t$ test for paired data. Missing data were not replaced unless a subject withdrew from the study because of poor tolerability, in which case the missing data were replaced with the worst case (bad tolerability) for the primary assessment measure. Statistical analysis was performed using SAS ${ }^{\circledR}$ version 9.3 (SAS Institute, Cary, NC, USA). All statistical tests were twotailed with a type I error of 0.05 .

\section{RESULTS}

\section{Subjects}

Sixty-one subjects (19 infants, 22 young children, and 20 adults) were included between December 22, 2014 and July 31, 2015. The study was completed on August 21, 2015. All subjects completed the study except for two children aged 2-6 years, one because of a lack of efficacy and the other because of personal reasons unrelated to the study or product. Proportions of male and female subjects were similar for the different age groups (Table 1). Most children had Fitzpatrick skin type II and most adults had Fitzpatrick skin type III. The baseline disease severity, as assessed by SCORAD index and IGA score, was similar in all age groups. About half the children but only $15 \%$ of adults had existing flares of $\mathrm{AD}$ at inclusion. Most children but less than half of adults had a known familial history of atopy.

\section{Compliance}

Almost all subjects $(59 / 61 ; 96.7 \%)$ applied the MDREC twice daily for more than $75 \%$ of the number of days they participated in the study. The overall compliance with the twice-daily regimen was high: for the total study population, on average, $95 \%$ of total possible applications were completed. 
Table 1 Subject characteristics $(N=61)$

\begin{tabular}{|c|c|c|c|}
\hline Characteristic & 3-23 months $(N=19)$ & $2-6$ years $(N=22)$ & $18-65$ years $(N=20)$ \\
\hline \multicolumn{4}{|l|}{ Sex, $n(\%)$} \\
\hline Male & $9(47.4)$ & $10(45.5)$ & $11(55.0)$ \\
\hline Female & $10(52.6)$ & $12(54.5)$ & $9(45.0)$ \\
\hline \multicolumn{4}{|l|}{ Age } \\
\hline Mean $\pm S D$ & $10.0 \pm 5.2$ months & $3.5 \pm 1.3$ years & $35.5 \pm 11.7$ years \\
\hline Range & 3-21 months & $2-5.8$ years & $18-58$ years \\
\hline \multicolumn{4}{|c|}{ Fitzpatrick skin type, $n(\%)$} \\
\hline I & $0(0.0)$ & $0(0.0)$ & $0(0.0)$ \\
\hline II & $15(79.0)$ & $13(59.0)$ & $5(25.0)$ \\
\hline III & $4(21.0)$ & $8(36.4)$ & $13(65.0)$ \\
\hline IV & $0(0.0)$ & $1(4.6)$ & $2(10.0)$ \\
\hline \multicolumn{4}{|c|}{ SCORAD index at inclusion } \\
\hline Mean \pm SD & $25.2 \pm 3.0$ & $24.7 \pm 3.5$ & $26.5 \pm 4.4$ \\
\hline \multicolumn{4}{|l|}{ IGA at inclusion, $n(\%)$} \\
\hline Mild (score $=2$ ) & $15(78.9)$ & $21(95.5)$ & $14(70.0)$ \\
\hline Moderate $($ score $=3$ ) & $4(21.1)$ & $1(4.5)$ & $6(30.0)$ \\
\hline \multicolumn{4}{|c|}{ Known history of atopy in subject's family, $n$ (\%) } \\
\hline Yes & $15(79.0)$ & $16(72.7)$ & $8(40.0)$ \\
\hline No & $4(21.0)$ & $6(27.3)$ & $12(60.0)$ \\
\hline \multicolumn{4}{|c|}{ Time between diagnosis and inclusion } \\
\hline Mean $\pm S D$ & $4.6 \pm 3.7$ months & $2.2 \pm 1.6$ years $^{\mathrm{a}}$ & $23.1 \pm 15.0$ years $^{\mathrm{b}}$ \\
\hline Range & $1-13$ months & $0-5.2$ years $^{\mathrm{a}}$ & $1-54$ years $^{\mathrm{b}}$ \\
\hline \multicolumn{4}{|c|}{ Existing $\mathrm{AD}$ flare at inclusion, $n(\%)$} \\
\hline Yes & $11(57.9)$ & $9(40.9)$ & $3(15.0)$ \\
\hline No & $8(42.1)$ & $13(59.1)$ & $17(85.0)$ \\
\hline
\end{tabular}

$I G A$ investigator's global assessment, $S C O R A D$ scoring atopic dermatitis, $S D$ standard deviation

a $n=19$

b $n=15$

\section{Tolerability}

On the basis of the period from week 1 until the end of the study (day 22), the local tolerability of the MDREC was judged by the investigators to be excellent for all (39/39) children and for
$90 \%(18 / 20)$ of adults (Table 2). The local tolerability was also judged as excellent for all subjects after first application of the MDREC (day 1) and as good to excellent after 1 week of twice-daily application (data not shown). 
Table 2 Investigator-assessed local tolerability for the period from day 8 to study end (day 22)

\begin{tabular}{lllll}
\hline Local tolerability, $\boldsymbol{N}(\mathbf{\%})$ & $\mathbf{3 - 2 3}$ months $(\boldsymbol{N}=\mathbf{1 9 )}$ & $\mathbf{2 - 6}$ years $(\boldsymbol{N}=\mathbf{2 0})$ & $\mathbf{1 8 - 6 5}$ years $(\boldsymbol{N}=\mathbf{2 0})$ & Overall $(\boldsymbol{N}=\mathbf{5 9})$ \\
\hline Excellent & $19(100.0)$ & $20(100.0)$ & $18(90.0)$ & $57(96.6)$ \\
Very good & $0(0.0)$ & $0(0.0)$ & $1(5.0)$ & $1(1.7)$ \\
Good & $0(0.0)$ & $0(0.0)$ & $1(5.0)$ & $1(1.7)$ \\
Moderate & $0(0.0)$ & $0(0.0)$ & $0(0.0)$ & $0(0.0)$ \\
Bad & $0(0.0)$ & $0(0.0)$ & $0(0.0)$ & $0(0.0)$ \\
\hline
\end{tabular}

\section{Safety}

Six subjects, all adults, had AEs considered related to the MDREC, all of which were mild, transient, and typically lasted 1-3 days. Most AEs were pruritus $(n=4)$ or redness $(n=4)$ at the site of product application. None of the subjects withdrew from the study, required modification of MDREC application, or required corrective treatment because of an AE. There were no serious AEs.

\section{Efficacy}

\section{Investigator-Assessed}

AD symptom severity, measured by investigators using the SCORAD index, progressively decreased in each age subgroup and in the whole population (Table 3). Between baseline and the end of the study on day 22 , the mean SCORAD index decreased by 12.9 points $(-50.6 \%)$ in the total population $(P<0.0001)$. At day 22, 55.9\% $(n=33)$ of the 59 subjects completing the study had an improved IGA score, $42.4 \%(n=25)$ had a stable score, and $1.7 \%(n=1)$ had a worse score.

\section{Subject-Assessed}

Subjects also reported that their AD progressively decreased in severity according to both the PO-SCORAD index and PGA score (Table 4). At day $22,17.5 \%$ of subjects reported total resolution of their $\mathrm{AD}, 31.6 \%$ reported a marked improvement, and $29.8 \%$ reported a slight improvement. More than $75.0 \%$ of subjects reported some degree of improvement by PGA at all follow-up time points compared to baseline (day 1).

\section{Skin Hydration and TEWL}

Skin hydration, measured by corneometry in adults only, was significantly higher at day 22 than at day 1 (Table 5). Also, mean TEWL was lower at day 8 and 22 than at day 1, although differences were not statistically significant.

\section{Satisfaction with MDREC}

According to questionnaires completed at the end of the study, around 95\% of subjects (or their parents or guardians) were satisfied with the MDREC. Subjects gave mean satisfaction scores greater than 5 for the MDREC assessed on a 10-point scale [7.3 \pm 2.4 for the 3-23 month group (mean $\pm \mathrm{SD}$ ), $8.1 \pm 1.7$ for the $2-6$ year group, $6.1 \pm 2.0$ for the adult group] and only one subject in each group (approx. 5\%) disliked the product. Subjects were generally satisfied with the MDREC's application and texture, reporting it as not overly sticky or greasy, and also reported their skin to be comfortable (93\% of subjects), soft to the touch (95\%), and less irritated (79\%) after application.

\section{DISCUSSION}

Many emollients are unsuitable for managing $\mathrm{AD}$ because they are cosmetics rather than $\mathrm{AD}$ tested, allergy-safe medical devices. These unverified emollients can be poorly tolerated 
Table 3 Investigator efficacy assessments

\begin{tabular}{|c|c|c|c|c|}
\hline Measure & Subcategory & Day 1 & Day 8 & Day 22 \\
\hline \multirow[t]{10}{*}{ SCORAD index, mean $\pm S D$} & \multirow[t]{2}{*}{ 3-23 months } & $N=19$ & $N=19$ & $N=19$ \\
\hline & & $25.2 \pm 3.0$ & $21.0 \pm 7.3$ & $14.0 \pm 8.8$ \\
\hline & \multirow[t]{2}{*}{$2-6$ years } & $N=22$ & $N=22$ & $N=20$ \\
\hline & & $24.7 \pm 3.5$ & $18.8 \pm 6.8$ & $9.9 \pm 6.1$ \\
\hline & \multirow[t]{2}{*}{$18-65$ years } & $N=20$ & $N=20$ & $N=20$ \\
\hline & & $26.5 \pm 4.4$ & $19.0 \pm 5.9$ & $13.7 \pm 7.9$ \\
\hline & \multirow[t]{2}{*}{ Overall } & $N=61$ & $N=61$ & $N=59$ \\
\hline & & $25.4 \pm 3.7$ & $19.6 \pm 6.6$ & $12.5 \pm 7.7$ \\
\hline & Change from day 1 & - & $-5.8 \pm 6.2$ & $-12.9 \pm 7.6$ \\
\hline & $P$ value vs. day $1^{a}$ & - & $<0.001$ & $<0.001$ \\
\hline \multirow[t]{7}{*}{ IGA score, $n(\%)$} & & $N=61$ & $N=61$ & $N=59$ \\
\hline & Clear & $0(0.0)$ & $0(0.0)$ & $10(17.0)$ \\
\hline & Almost clear & $0(0.0)$ & $13(21.3)$ & $17(28.8)$ \\
\hline & Mild & $50(82.0)$ & $41(67.2)$ & $29(49.2)$ \\
\hline & Moderate & $11(18.0)$ & $7(11.5)$ & $3(5.1)$ \\
\hline & Severe & $0(0.0)$ & $0(0.0)$ & $0(0.0)$ \\
\hline & $P$ value vs. day $1^{\mathrm{b}}$ & - & $<0.001$ & $<0.001$ \\
\hline \multirow[t]{3}{*}{ IGA score change from day $1, n(\%)$} & Improved & - & $17(27.9)$ & $33(55.9)$ \\
\hline & Unchanged & - & $42(68.9)$ & $25(42.4)$ \\
\hline & Worse & - & $2(3.3)$ & $1(1.7)$ \\
\hline
\end{tabular}

IGA investigator's global assessment, SCORAD scoring atopic dermatitis, $S D$ standard deviation

${ }^{a}$ Paired Student $t$ test compared to day 1

b Wilcoxon signed rank test compared to day 1

when applied directly on skin lesions, and may interfere with medications used to treat $\mathrm{AD}$ flares [17]. In the current study, we showed that the tested MDREC, applied to active inflamed skin lesions or areas of dry skin twice-daily for 3 weeks, was well tolerated by infants, young children, and adults with mild to moderate AD, even those that had existing AD flares. None of the children in the study had AEs suspected to be related to the MDREC, although some adults reported mild, transient pruritus and erythema related to product application. However, these were expected because the product was directly applied to active, inflamed lesions [5, 17-19], and they did not affect local tolerability measured at the end of study. Importantly, none of the subjects discontinued using the MDREC because of an AE. Thus, the MDREC could be applied on skin lesions with little discomfort, an important factor when considering emollients for AD management.

Poor adherence to topical medication regimens is an obstacle to managing $\mathrm{AD}$ and often explains why many treatments fail [20]. Despite this, adherence was high in all age groups, which suggests that subjects were satisfied with 
Table 4 Subject efficacy assessments

\begin{tabular}{|c|c|c|c|c|c|}
\hline Measure & Subcategory & Day 1 & Day 8 & Day 15 & Day 22 \\
\hline \multirow[t]{10}{*}{ PO-SCORAD index, mean $\pm S D$} & 3-23 months & $N=19$ & $N=19$ & $N=18$ & $N=18$ \\
\hline & & $25.5 \pm 9.4$ & $20.2 \pm 13.0$ & $18.5 \pm 16.3$ & $17.4 \pm 15.0$ \\
\hline & $2-6$ years & $N=22$ & $N=21$ & $N=19$ & $N=20$ \\
\hline & & $24.9 \pm 8.8$ & $16.8 \pm 10.0$ & $13.9 \pm 10.7$ & $10.7 \pm 9.2$ \\
\hline & $18-65$ years & $N=20$ & $N=20$ & $N=20$ & $N=20$ \\
\hline & & $32.7 \pm 12.0$ & $21.9 \pm 12.4$ & $19.3 \pm 9.5$ & $18.7 \pm 10.8$ \\
\hline & Overall & $N=61$ & $N=60$ & $N=57$ & $N=58$ \\
\hline & & $27.6 \pm 10.6$ & $19.6 \pm 11.8$ & $17.3 \pm 12.4$ & $15.6 \pm 12.1$ \\
\hline & Change from day 1 & & $-8.1 \pm 9.8$ & $-10.4 \pm 10.4$ & $-12.2 \pm 10.8$ \\
\hline & $P$ value vs. day $1^{\mathrm{a}}$ & - & $<0.001$ & $<0.001$ & $<0.001$ \\
\hline \multirow[t]{7}{*}{ PGA score, $n$ (\%) } & & & $N=60$ & $N=59$ & $N=57$ \\
\hline & Total resolution & - & $1(1.7)$ & $6(10.2)$ & $10(17.5)$ \\
\hline & Marked improvement & - & $12(20.0)$ & $17(28.8)$ & $18(31.6)$ \\
\hline & Slight improvement & - & $36(60.0)$ & $22(37.3)$ & $17(29.8)$ \\
\hline & No change & - & $5(8.3)$ & $11(18.6)$ & $9(15.8)$ \\
\hline & Worse & - & $6(10.0)$ & $3(5.1)$ & $3(5.3)$ \\
\hline & $P$ value vs. day $1^{\mathrm{b}}$ & - & - & 0.006 & $<0.001$ \\
\hline
\end{tabular}

$P G A$ patient global assessment, $P O-S C O R A D$ patient-oriented scoring atopic dermatitis, $S D$ standard deviation

a Paired Student $t$ test compared to day 1

b Wilcoxon signed rank test compared to day 1

using the product as directed. Indeed, surveys at the end of the study confirmed that subjects liked the product. Admittedly, treatment adherence might have been improved by the short time between follow-ups in this study [20] and by the fact that subjects were in a clinical trial.

The MDREC appeared to be effective in alleviating $\mathrm{AD}$ symptoms in most subjects according to several extensively used investigator- and subject-based evaluations [21-25]. It also improved skin hydration in adults, which may help address the underlying problems of reduced skin barrier disruption and dryness in
$\mathrm{AD}[5,26]$. Other emollients have been similarly reported to reduce $\mathrm{AD}$ severity $[5,18,19]$, although they are rarely evaluated in subjects with AD flares at baseline. However, our study was limited in that it was uncontrolled, openlabel, and not specifically designed to assess efficacy. The study was also relatively small, although children were well represented. Although an intra-individual randomized controlled study showed the product to accelerate healing of $\mathrm{AD}$ lesions when used with topical corticosteroids [11], the product's efficacy and participant satisfaction with the MDREC alone 
Table 5 Skin hydration and TEWL in adults $(N=20)$

\begin{tabular}{llll}
\hline Measure & Mean \pm SD & Mean change from day $\mathbf{1} \pm$ SD & P value vs. day $\mathbf{1}$ \\
\hline Skin hydration & & & \\
Day 1 & $28.8 \pm 16.5$ & - & - \\
Day 8 & $32.3 \pm 17.0$ & $3.5 \pm 13.6$ & 0.26 \\
Day 22 & $34.9 \pm 19.2$ & $6.1 \pm 9.9$ & 0.01 \\
TEWL & & & - \\
Day 1 & $35.3 \pm 20.6$ & - & 0.40 \\
Day 8 & $32.7 \pm 17.0$ & $-2.5 \pm 13.2$ & 0.48 \\
Day 22 & $32.6 \pm 21.7$ & $-2.6 \pm 16.3$ & \\
\hline
\end{tabular}

$P$ values for change from day 1 determined by paired Student $t$ test

$T E W L$ transepidermal water loss, $S D$ standard deviation

should be confirmed in larger, dedicated clinical studies.

\section{CONCLUSIONS}

These results suggest that this new MDREC is safe and well tolerated when applied to AD skin lesions and dry flexural skin areas in infants, young children, and adults. It may therefore be beneficial when included as part of a daily skincare routine for patients with $\mathrm{AD}$.

\section{ACKNOWLEDGEMENTS}

We thank the study participants for their involvement in the study.

Funding. Sponsorship for this study and article processing charges were funded by Laboratoires Dermatologiques Ducray, Pierre Fabre Dermo-Cosmétique, Boulogne, France. All authors had full access to all of the data in this study and take complete responsibility for the integrity of the data and accuracy of the data analysis.

Authorship. All named authors meet the International Committee of Medical Journal Editors (ICMJE) criteria for authorship for this article, take responsibility for the integrity of the work as a whole, and have given their approval for this version to be published.

Medical Writing, Editorial, and Other Assistance. The authors would like to thank Valérie Mengeaud (Medical Director, Laboratoires Dermatologiques Ducray, Pierre Fabre Dermo-Cosmétique, France) for critically reviewing the manuscript; Jens Milde, Isabella Stapff-Bauer, and Marius Wegner (Pharmalog, Ismaning, Germany) for supporting the study; Christophe Lauze (Biometry Department, Pierre Fabre Dermo-Cosmétique, France) for statistical support; Magali Debure (Pierre Fabre DermoCosmétique, France) for data management; Catherine Bidan (Pierre Fabre Dermo-Cosmétique, France) for formulating the MDREC; and the study investigators (Drs. Georg Popp, Henrik Prés, Katrin Biebach, Michael Sebastian, and Professor Carl-Peter Bauer) and their co-investigators for recruiting and evaluating the patients. Medical writing was provided by Dr. Jonathan Pitt (4Clinics, Paris, France) and funded by Pierre Fabre Dermo-Cosmétique.

Disclosures. Andreas Pinter has worked as an investigator, speaker, or advisor for AbbVie, Allmirall-Hermal, Amgen, Biogen Idec, Boehringer-Ingelheim, Celgene, EliLilly, GSK, Galderma, Hexal, Janssen Cilag, LEO-Pharma, Medac, Merck Serono, Mitsubishi, 
MSD, Novartis, Pierre Fabre Dermo-Cosmétique, Pfizer, Tigercat Pharma, Regeneron, Roche, Sandoz Biopharmaceuticals, Schering-Plough, and UCB Pharma. Marie-Dominique Thouvenin was an employee of Pierre Fabre Dermo-Cosmétique when the study was conducted. Adeline Bacquey was an employee of Pierre Fabre Dermo-Cosmétique when the study was conducted. Anna Beatris Rossi was an employee of Pierre Fabre Dermo-Cosmétique when the study was conducted. Thérèse Nocera was an employee of Pierre Fabre Dermo-Cosmétique when the study was conducted.

Compliance with Ethics Guidelines. The study protocol was approved by the Ethics Committee of the Medical University Department of University Clinic Frankfurt am Main, Germany. All procedures performed in studies involving human participants were in accordance with the ethical standards of the institutional and/or national research committee and with the 1964 Helsinki Declaration and its later amendments or comparable ethical standards. Informed consent was obtained from all individual participants included in the study.

Data Availability. All data generated or analyzed during this study are included in this published article.

Open Access. This article is distributed under the terms of the Creative Commons Attribution-NonCommercial 4.0 International License (http://creativecommons.org/licenses/ by-nc/4.0/), which permits any noncommercial use, distribution, and reproduction in any medium, provided you give appropriate credit to the original author(s) and the source, provide a link to the Creative Commons license, and indicate if changes were made.

\section{REFERENCES}

1. Nutten S. Atopic dermatitis: global epidemiology and risk factors. Ann Nutr Metab. 2015;66(Suppl 1):8-16.

2. Leung DY, Bieber T. Atopic dermatitis. Lancet. 2003;361:151-60.
3. Asher MI, Montefort S, Bjorksten B, et al. Worldwide time trends in the prevalence of symptoms of asthma, allergic rhinoconjunctivitis, and eczema in childhood: ISAAC phases one and three repeat multicountry cross-sectional surveys. Lancet. 2006;368:733-43.

4. Blome C, Radtke MA, Eissing L, Augustin M. Quality of life in patients with atopic dermatitis: disease burden, measurement, and treatment benefit. Am J Clin Dermatol. 2016;17:163-9.

5. Catherine Mack Correa M, Nebus J. Management of patients with atopic dermatitis: the role of emollient therapy. Dermatol Res Pract. 2012;2012:836931.

6. Eichenfield LF, Tom WL, Berger TG, et al. Guidelines of care for the management of atopic dermatitis: section 2. Management and treatment of atopic dermatitis with topical therapies. J Am Acad Dermatol. 2014;71:116-32.

7. Loden $\mathrm{M}$, Andersson AC, Lindberg M. Improvement in skin barrier function in patients with atopic dermatitis after treatment with a moisturizing cream (Canoderm). Br J Dermatol. 1999;140:264-7.

8. Elias PM, Hatano Y, Williams ML. Basis for the barrier abnormality in atopic dermatitis: outsideinside-outside pathogenic mechanisms. J Allergy Clin Immunol. 2008;121:1337-433.

9. Loden M, Wiren K, Smerud K, et al. Treatment with a barrier-strengthening moisturizer prevents relapse of hand-eczema. An open, randomized, prospective, parallel group study. Acta Derm Venereol. 2010;90:602-6.

10. van Zuuren EJ, Fedorowicz Z, Christensen R, Lavrijsen A, Arents BW. Emollients and moisturisers for eczema. Cochrane Database Syst Rev. 2017;2:CD012119.

11. Rossi AB, Bacquey A, Nocera $T$, Thouvenin MD. Efficacy and tolerability of a medical device repairing emollient cream associated with a topical corticosteroid in adults with atopic dermatitis: an open-label, intra-individual randomized controlled study. Dermatol Ther (Heidelb). 2018;8:217-28.

12. Stamatas GN, Nikolovski J, Luedtke MA, Kollias N, Wiegand BC. Infant skin microstructure assessed in vivo differs from adult skin in organization and at the cellular level. Pediatr Dermatol. 2010;27:125-31.

13. European Commission. Medical devices: Guidance document-Classification of medical devices. Guidelines relating to the application of the council directive 93/42/EEC on medical devices; 2010. 
14. European Task Force on Atopic Dermatitis. Severity scoring of atopic dermatitis: the SCORAD index. Consensus Report of the European Task Force on Atopic Dermatitis. Dermatology. 1993;186:23-31.

15. Eichenfield LF, Tom WL, Chamlin SL, et al. Guidelines of care for the management of atopic dermatitis: section 1. Diagnosis and assessment of atopic dermatitis. J Am Acad Dermatol. 2014;70:338-51.

16. Vourc'h-Jourdain M, Barbarot S, Taieb A, et al. Patient-oriented SCORAD: a self-assessment score in atopic dermatitis. A preliminary feasibility study. Dermatology. 2009;218:246-51.

17. Wollenberg A, Oranje A, Deleuran M, et al. ETFAD/ EADV Eczema task force 2015 position paper on diagnosis and treatment of atopic dermatitis in adult and paediatric patients. J Eur Acad Dermatol Venereol. 2016;30:729-47.

18. Abramovits W, Boguniewicz M. A multicenter, randomized, vehicle-controlled clinical study to examine the efficacy and safety of MAS063DP (Atopiclair) in the management of mild to moderate atopic dermatitis in adults. J Drugs Dermatol. 2006;5:236-44.

19. Patrizi A, Capitanio B, Neri I, et al. A double-blind, randomized, vehicle-controlled clinical study to evaluate the efficacy and safety of MAS063DP (ATOPICLAIR) in the management of atopic dermatitis in paediatric patients. Pediatr Allergy Immunol. 2008;19:619-25.

20. Bass AM, Anderson KL, Feldman SR. Interventions to increase treatment adherence in pediatric atopic dermatitis: a systematic review. J Clin Med. 2015;4:231-42.

21. Giordano-Labadie F, Cambazard F, Guillet G, Combemale P, Mengeaud V. Evaluation of a new moisturizer (Exomega milk) in children with atopic dermatitis. J Dermatol Treat. 2006;17:78-81.

22. Chamlin SL, Kao J, Frieden IJ, et al. Ceramidedominant barrier repair lipids alleviate childhood atopic dermatitis: changes in barrier function provide a sensitive indicator of disease activity. J Am Acad Dermatol. 2002;47:198-208.

23. Grimalt R, Mengeaud V, Cambazard F. The steroidsparing effect of an emollient therapy in infants with atopic dermatitis: a randomized controlled study. Dermatology. 2007;214:61-7.

24. Msika P, De Belilovsky C, Piccardi N, Chebassier N, Baudouin C, Chadoutaud B. New emollient with topical corticosteroid-sparing effect in treatment of childhood atopic dermatitis: SCORAD and quality of life improvement. Pediatr Dermatol. 2008;25:606-12.

25. Futamura M, Leshem YA, Thomas KS, Nankervis $H$, Williams HC, Simpson EL. A systematic review of Investigator Global Assessment (IGA) in atopic dermatitis (AD) trials: many options, no standards. J Am Acad Dermatol. 2016;74:288-94.

26. Sator PG, Schmidt JB, Honigsmann H. Comparison of epidermal hydration and skin surface lipids in healthy individuals and in patients with atopic dermatitis. J Am Acad Dermatol. 2003;48:352-8. 